\section{(6) OPEN ACCESS}

\title{
Patient-reported quality of life outcomes for children with serious congenital heart defects
}

\author{
Rachel L Knowles, ${ }^{1}$ Thomas Day, ${ }^{1}$ Angie Wade, ${ }^{1}$ Catherine Bull, ${ }^{2}$ Christopher Wren, ${ }^{3}$ \\ Carol Dezateux, ${ }^{1}$ On behalf of the UK Collaborative Study of Congenital Heart Defects \\ (UKCSCHD)
}

\begin{abstract}
- Additional material is published online only. To view please visit the journal online (http://dx.doi.org/10.1136/ archdischild-2013-305130).

${ }^{1} \mathrm{MRC}$ Centre of Epidemiology for Child Health, Centre of Paediatric Epidemiology and Biostatistics, UCL Institute of Child Health, University College London, London, UK

${ }^{2}$ Cardiac Unit, Great Ormond Street Hospital for Children NHS Trust, London, UK ${ }^{3}$ Department of Paediatric Cardiology, Freeman Hospital, Newcastle-upon-Tyne, UK
\end{abstract}

\section{Correspondence to} Dr Rachel L Knowles, MRC Centre of Epidemiology for Child Health, UCL Institute of Child Health, 30 Guilford Street, London WC1N 1EH, UK; rachel.knowles@ucl.ac.uk

Received 24 August 2013 Revised 2 December 2013 Accepted 13 December 2013

Published Online First

9 January 2014

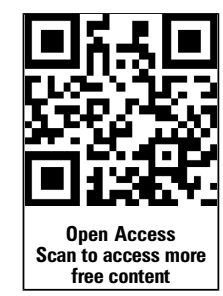

\footnotetext{
To cite: Knowles RL, Day T, Wade A, et al. Arch Dis Child 2014;99:413-419.
}

\begin{abstract}
Objective To compare patient-reported, health-related quality of life (QoL) for children with serious congenital heart defects (CHDs) and unaffected classmates and to investigate the demographic and clinical factors

influencing QoL.

Design Retrospective cohort study.

Setting UK National Health Service.

Patients UK-wide cohort of children with serious CHDs aged 10-14 years requiring cardiac intervention in the first year of life in one of 17 UK paediatric cardiac surgical centres operating during 1992-1995. A comparison group of classmates of similar age and sex was recruited.
\end{abstract}

Main outcome measures Child self-report of healthrelated QoL scores (Pediatric Quality of Life Inventory, PedsQL) and parental report of schooling and social activities.

Results Questionnaires were completed by 477 children with CHDs (56\% boys; mean age 12.1 (SD 1.0) years) and 464 classmates (55\%; 12.0 (SD 1.1) years). Children with CHDs rated QoL significantly lower than classmates (CHDs: median 78.3 (IQR 65.0-88.6); classmates: 88.0 (80.2-94.6)) and scored lower on physical (CHDs: 84.4; classmates: 93.8; difference 9.4 (7.8 to 10.9)) and psychosocial functioning subscales (CHDs: 76.7, classmates: 85.0; difference 8.3 (6.0 to 10.6)). Cardiac interventions, school absence, regular medications and non-cardiac comorbidities were independently associated with reduced QoL. Participation in sport positively influenced QoL and was associated with higher psychosocial functioning scores.

Conclusions Children with serious CHDs experience lower QoL than unaffected classmates. This appears related to the burden of clinical intervention rather than underlying cardiac diagnosis. Participation in sports activities is positively associated with increased emotional well-being. Child self-report measures of QoL would be a valuable addition to clinical outcome audit in this age group.

\section{INTRODUCTION}

Increasing numbers of children operated in infancy for serious congenital heart defects (CHDs) are surviving through childhood and into adulthood. ${ }^{1}$ As mortality falls for these children, broader health outcomes of significance to children and their families, such as health-related quality of life (QoL) and the capacity for social and educational participation attain greater importance. ${ }^{2}$ Over a decade ago, the Bristol Inquiry ${ }^{3}$ report into the care of children undergoing cardiac surgery highlighted the

\section{What is already known}

- Health, educational and quality of life (QoL) outcomes have increasing relevance to children with serious congenital heart defects (CHDs), who can now expect to survive into adulthood.

- Studies comparing health-related QoL outcomes of school-age children with serious CHDs and their classmate peers are lacking.

- Children's own self-reported views are important outcome measures as the child's perspective often differs from parents.

\section{What this study adds}

- Ten to 14-year-olds with serious congenital heart defect (CHDs) report significantly lower health-related quality of life than unaffected classmates.

- This reduction is related to the burden of clinical intervention and on-going care rather than cardiac diagnosis; sports participation offers positive benefit to psychosocial functioning.

- Collection of child-reported outcomes for CHDs is practicable and its inclusion in routine national clinical outcome monitoring and audit should be considered.

lack of long-term outcome data for children with CHDs and underlined the need for a national monitoring system. Although short-term cardiac surgical outcomes for UK children are now comprehensively collected by the Central Cardiac Audit Database and published through the NICORCongenital Heart Disease Portal, ${ }^{4}$ the quality of long-term survival at a national level is not routinely captured.

Patient-reported experiences and outcomes are central to quality improvements within the National Health Service (NHS) ${ }^{5}$ and are increasingly being advocated for monitoring individual clinical care, ${ }^{67}$ which has led to an expansion in instruments designed to measure well-being, QoL and healthcare experience. Patient-reported outcome measures (PROMS) ascertain the patient's own assessment of their health, functional status and QoL. The application of PROMS in clinical 
practice and outcomes research is pertinent to all chronic childhood disorders, of which CHDs are a key example, as outcomes will vary across the lifetime influenced by children's adaptation to their changing environment and particularly the transition to adulthood. While age-adapted questionnaires specifically suited to self-reporting of health outcomes by children have multiplied, there remains a reliance on proxy reporting by parents. Although parental perspectives are useful, QoL and patient experience are subjective concepts. Consequently children's own views on their health and well-being should be assessed. Moreover, evidence suggests that children's views are reliable and can differ greatly from the views of their parents or education and health professionals. ${ }^{8}$

QoL measures focus on daily life experiences and outcomes during childhood and adolescence and facilitate the development of interventions to support families and promote resilience, or positive adaptation, in long-term survivors with chronic disorders. ${ }^{9}$ A limited number of multidimensional patient selfreport instruments have been validated to explore the child's perspective on health and well-being in paediatric cardiac populations, including the impact of a CHD on current lifestyle, past experience and future expectations. ${ }^{2}{ }^{10-12}$ The Pediatric Quality of Life Inventory (PedsQL 4.0$)^{13}$ is a widely employed generic QoL instrument for children aged 2-18 years; the questionnaire may be self-completed by children aged 5 years or over.

Our aims were to estimate and compare QoL scores reported using the PedsQL 4.0 by a UK-wide cohort of school-age children with serious CHDs, with a comparison group comprised of their unaffected classmates and to investigate the factors that influence self-reported outcomes for children living with chronic or congenital conditions.

\section{METHODS}

The UK Collaborative Study of CHDs (UKCSCHD) is a multicentre prospective study of almost 4000 children, born 19921995 with serious CHDs requiring intervention within the first year of life and involving all 17 UK paediatric cardiac centres operating at that time. The cohort excluded children with minor defects not requiring intervention, ${ }^{14}$ but included around one-third of all children with CHDs (2/1000 live births). Information, including sex, cardiac diagnosis and cardiac procedures, was obtained from individual case notes review. Each child was assigned a primary cardiac diagnosis using Wren's hierarchy ${ }^{14}$ and a diagnosis-derived cardiac prognostic severity (CPS) score, adapted from Lane ${ }^{15}$ (see online supplementary table S1). Research ethics approval (Trent MREC 04/4/017) was given for local cardiologists to contact surviving children with an invitation to participate in the postal questionnaire follow-up of QoL, health and educational outcomes.

During 2004-2007, local collaborating cardiologists attempted to contact 2963 surviving children, then aged 1014 years (figure 1). Due to restrictions imposed by ethics and governance approvals, ${ }^{16}$ families could only be contacted by the local clinical care team after approval by the child's cardiologist and general practitioner; we estimate that around $70 \%$ of eligible children received an invitation to participate. Of 853 children who agreed to take part, 515 (60.3\%) returned a questionnaire; 38 were subsequently excluded due to incomplete responses (figure 1). In addition, parents returned a parent questionnaire for 19 children who did not return the child questionnaire; 12 of these children were reported by parents to have significant learning difficulties which may account for noncompletion. Participants were asked to recruit a comparison group by giving additional questionnaires to their two classmates closest in age and of the same sex. We received questionnaires from 479 classmates; 15 were excluded as incomplete/ ineligible.

Each child completed the PedsQL 4.0 questionnaire (UK English version). Items are scored on a Likert scale from 0 (never a problem) to 4 (almost always a problem) then transformed to a 0-100 scale to provide physical functioning, psychosocial (school, social and emotional) functioning and summary scores; higher scores represented a better QoL. ${ }^{13}$ Scores were not calculated if more than half the scale items were incomplete (physical scale incomplete $(n=3)$; emotional scale incomplete $(n=1))$. We estimated the minimal clinically important difference (MCID), defined as the minimum score increase on a QoL scale for a treatment to be considered of patient benefit and compared this with
Figure 1 Flow diagram of recruitment and response to questionnaires. *Contact with families by researchers was dependent on the local clinician obtaining consent to contact from each child's general practitioner (GP). If a GP did not provide written consent or did not respond, questionnaires were not sent to the family. This procedure was mandated by the research ethics committee in order to protect patient confidentiality and the central study team did not receive details of local response rates. On this basis of the London mailing, which did involve members of the study team, we estimate that only $70 \%$ of survivors were sent an invitation to participate, but a proportion of these were addressed incorrectly and/or returned unopened. Throughout the UK, 853 families agreed to receive a questionnaire and $515(60.3 \%)$ of these were returned completed.

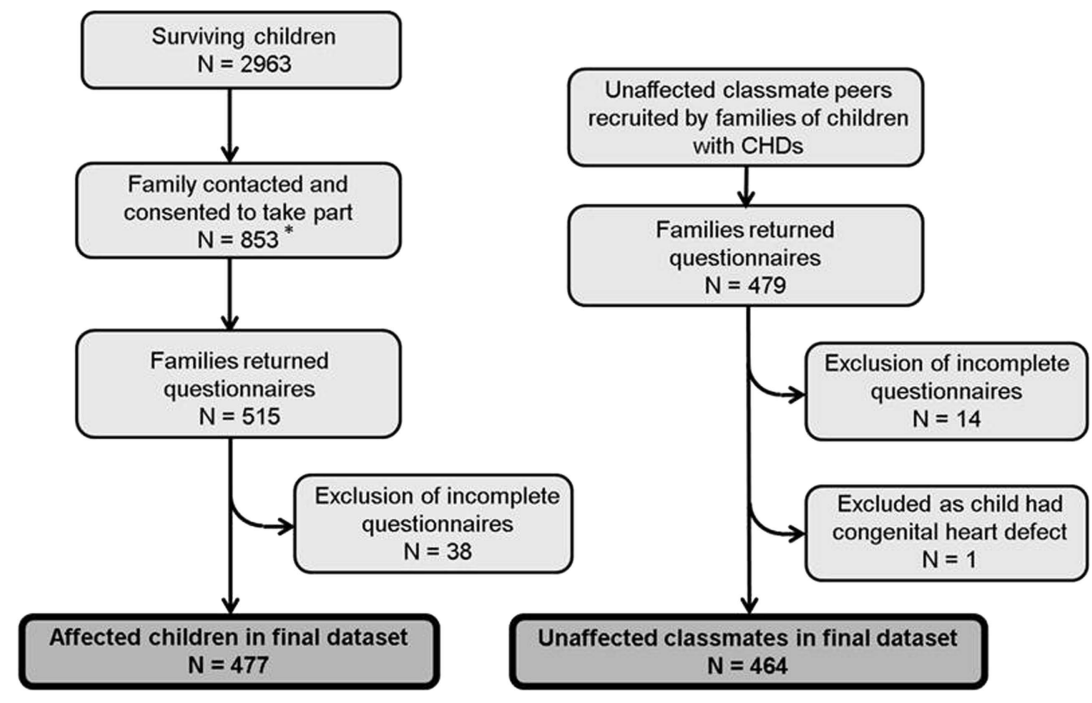


the MCID of 4.4 points attributed to the unadjusted Child Report PedsQL Summary Scale. ${ }^{13}$

Parents (including carers or guardians acting in a parental role) completed a questionnaire, providing information about their employment, education, family and their child's health, schooling and daily activities. Parental employment was full time (1.0) or part-time (0.5) for each parent, then summed. Parents reported regular medications (classified as cardiac or non-cardiac), vision, hearing or speech problems, special educational needs provision, school absences and participation in sporting and social activities for their child. Parents were asked whether they considered their child to have a long-standing non-cardiac illness, and if so, whether this limited their child's activities. $^{17}$

\section{Statistical analysis}

Participant characteristics were examined for response bias. As PedsQL scores were not normally distributed, median scores were compared between groups and 95\% CIs for the difference in medians estimated. ${ }^{18}$ To explore factors influencing outcome, we developed univariable and multivariable regression models, using Generalised Additive Models for Location, Scale and Shape (GAMLSS) based on the Sinh-Arcsinh (SHASH) distribution, to take account of the non-normal outcome distribution. ${ }^{19}{ }^{20} \mathrm{~A}$ forward variable-selection approach was used and variables retained if they improved goodness-of-fit, based on the Akaike information criterion. We assessed the need for a multilevel model to account for correlation within cardiac centres and case-control clusters; no evidence of correlation within cardiac centres was found and we adjusted for clustering of cases and controls by including three levels of school-type factors (mainstream school, mainstream school with learning support or special school/unit) in regression models.

Sensitivity analyses explored the effect of excluding children who did not recruit classmates, as these children were more likely to attend special schools. Statistical analyses were performed in R V.12.2.1 (R Foundation for Statistical Computing, Austria).

\section{RESULTS}

Data from 477 affected children (268 boys (56\%); mean age 12.1 (SD 1.0) years) and 464 classmates (255 boys (55\%); mean age 12.0 (SD 1.1) years) were analysed. Characteristics of children with CHDs were compared with non-responding survivors $(n=2486)$ in the UKCSCHD cohort (see online supplementary table S1). Children returning questionnaires were representative of all primary cardiac diagnoses, although children with more severe CPS scores (palliated CHDs) appeared more likely to return questionnaires. Characteristics of affected children and classmates were compared (table 1); children with CHDs were on average $200 \mathrm{~g}$ lighter at birth, more likely to take regular medications, have associated health problems and health-related absences from school and participated less frequently in sport and social activities.

Unadjusted median PedsQL physical functioning, psychosocial functioning and summary scores for children with CHDs and unaffected classmates differed significantly (figure 2). The unadjusted median summary score was 78.3 (IQR 65.0-88.6) for the affected children, compared to 88.0 (80.2-94.6) for unaffected classmates (difference 9.8 (95\% CI 7.1 to 12.4)). Unadjusted median physical and psychosocial functioning scores for children with CHDs were (84.4 (65.6-93.8) and 76.7 (62.5-86.7)), respectively; difference 9.4 (95\% CI 7.8 to 10.9)) and significantly lower than for unaffected classmates $(93.8$
(84.0-100.0) and 85.0 (76.7-93.3), respectively; difference 8.3 (95\% CI 6.0 to 10.6$)$ ).

In univariable regression models (see online supplementary table S2), factors significantly associated with lower scores included worse CPS score, increasing number of cardiac interventions, long-standing limiting non-cardiac illness, regular medications, longer school absence, and vision or speech problems. Hearing difficulties were associated with worse psychosocial functioning and summary scores only. Increasing frequency of sporting and social activities was associated with higher PedsQL scores, and higher psychosocial functioning and summary scores were associated with both parents living in the family home and parents in employment.

In multivariable models (table 2), adjusting for school-type and sociodemographic factors such as parent education or employment, having a CHD remained an independent predictor of significantly worse summary, physical and psychosocial functioning scores. Non-cardiac comorbidities, indicated by limiting long-standing illness and regular medications, were also independently associated with poorer outcomes. Visual or hearing difficulties were associated with lower summary scores only, whereas school absence was associated with poorer summary and psychosocial, but not physical, functioning scores. Increased frequency of sports participation remained associated with better summary and psychosocial, but not physical, functioning scores (table 3A). Individual child age, sex or ethnicity, and parental educational or employment, did not independently influence self-reported QoL for children in our study. These findings persisted in sensitivity analyses.

For children with CHDs physical functioning, psychosocial functioning and summary scores decreased significantly as the number of cardiac interventions increased; conversely the diagnosis-based CPS score was not associated with outcome (table 3B).

\section{DISCUSSION}

Our study demonstrates that children with serious CHDs report significantly impaired QoL compared with their unaffected classmates, with unadjusted median scores 8-10 points lower on the summary, physical and psychosocial functioning PedsQL scales. The difference we observed between affected children and their classmates exceeds the MCID for the PedsQL summary scale and therefore has clinical relevance. Significant differences persisted after adjustment for age, sex, ethnicity and sociodemographic factors. Specific CHD diagnosis was not associated with QoL, whereas a higher cumulative burden of cardiac interventions over the lifetime had a significant negative impact. Additional factors associated with reduced QoL independently of having a CHD were non-cardiac comorbidities, specifically long-standing limiting non-cardiac illness, vision or hearing difficulties, and the need to take regular medications or time off from school for health reasons. Our findings suggest that children whose full inclusion in school and social activities is limited by a chronic disorder, whether this is cardiac or noncardiac, experience lower subjective QoL.

Latal $^{2}$ identified seven studies in which QoL after cardiac surgery was measured using child self-report instruments. Study findings were inconsistent, which could be related to instrument heterogeneity or variable participant selection. In studies of children with chronic conditions, worse PedsQL scores were reported by children with cardiac defects in comparison with population norms $^{10}{ }^{21-23}$ or 'healthy' comparison groups. ${ }^{24-26}$ Children with more 'severe' CHDs rated QoL lower, although 'severe' was variously defined as cyanosis, ${ }^{24}$ or type of intervention. ${ }^{10}{ }^{21}$ 
Table 1 Characteristics of affected children and their classmates participating in the study

\begin{tabular}{|c|c|c|c|c|c|}
\hline & \multicolumn{2}{|c|}{$\begin{array}{l}\text { Children with CHDs } \\
\mathrm{N}=477\end{array}$} & \multicolumn{2}{|c|}{$\begin{array}{l}\text { Unaffected classmates } \\
\mathrm{N}=464\end{array}$} & \multirow[b]{2}{*}{$\mathrm{p}$ Value for difference } \\
\hline & $\mathrm{N}(\%)$ & Missing (N (\%)) & $\mathrm{N}(\%)$ & Missing (N (\%)) & \\
\hline \multicolumn{6}{|l|}{ Individual factors } \\
\hline Male & $268(56)$ & 0 & $255(55)$ & 0 & 0.63 \\
\hline Age (years) & $12.1(1.0)^{*}$ & 0 & $12.0(1.1)^{*}$ & 0 & 0.33 \\
\hline Ethnicity & & $4(1)$ & & $7(2)$ & 0.24 \\
\hline White & $443(93)$ & & $420(90)$ & & \\
\hline Non-white & $30(6)$ & & $37(8)$ & & \\
\hline Birth weight $(g)$ & $3228(673.5)^{*}$ & 16 & $3443(603.0)^{*}$ & 15 & $<0.001$ \\
\hline \multicolumn{6}{|l|}{ Parent $\dagger$ and family factors } \\
\hline Parental education level & & 0 & & 0 & 0.14 \\
\hline None/General Certificate of Secondary Education & $168(35)$ & & $142(31)$ & & \\
\hline A level & $140(29)$ & & $129(28)$ & & \\
\hline Degree & 169 (36) & & $193(41)$ & & \\
\hline Number of full-time equivalent working parentst & $1.2(0.58)^{*}$ & 0 & $1.3(0.56)^{*}$ & 0 & 0.19 \\
\hline Number of siblings at home & $2.0[2.0-2.0] \ddagger$ & 0 & $2.0[2.0,2.0] \ddagger$ & 0 & 0.44 \\
\hline Two parentst at home at birth & $452(95)$ & 0 & $444(96)$ & 2 & 0.22 \\
\hline Two parentst at home now & $385(81)$ & 0 & $364(78)$ & 1 & 0.43 \\
\hline Mother's age at child's birth (years) & $29.6(5.1)^{*}$ & 6 & $29.8(4.8)^{*}$ & 8 & 0.53 \\
\hline Father's age at child's birth (years) & $32.1(6.1)^{*}$ & 11 & $32.0(5.9)^{*}$ & 11 & 0.86 \\
\hline \multicolumn{6}{|l|}{ Comorbidities } \\
\hline Non-cardiac long-standing illness & & 20 & & 13 & $<0.001$ \\
\hline Yes, not limiting & $66(14)$ & & $48(10)$ & & \\
\hline Yes, limiting & $111(23)$ & & $31(7)$ & & \\
\hline Uses regular non-cardiac medications & $170(36)$ & 3 & $40(9)$ & 7 & $<0.001$ \\
\hline Problems with vision & $164(34)$ & 14 & $109(23)$ & 12 & $<0.001$ \\
\hline Problems with hearing & $124(26)$ & 5 & $69(10)$ & 10 & $<0.001$ \\
\hline Problems with speech & $70(15)$ & 9 & $13(3)$ & 7 & $<0.001$ \\
\hline \multicolumn{6}{|l|}{ School and daily life activities } \\
\hline Type of schooling & & 0 & & 0 & $<0.001$ \\
\hline Mainstream school & $326(68)$ & & $418(90)$ & & \\
\hline Mainstream with assistance & $112(23)$ & & $40(9)$ & & \\
\hline Special school/unit & $39(8)$ & & $6(1)$ & & \\
\hline School absence in last year & & 4 & & 5 & $<0.001$ \\
\hline Never & $105(22)$ & & $148(32)$ & & \\
\hline$<1$ week & $193(40)$ & & $227(49)$ & & \\
\hline $1-2$ weeks & $102(21)$ & & $56(12)$ & & \\
\hline 2 weeks-1 month & $46(10)$ & & $20(4)$ & & \\
\hline$>1$ month & $28(6)$ & & $8(2)$ & & \\
\hline Frequency of sport§ & $1.0[0.5-3.0] \ddagger$ & 0 & $2.0(1.0-3.0) \neq$ & 0 & $<0.001$ \\
\hline Frequency of social activities? & $5.0[2.5-6.5] \ddagger$ & 0 & $6.0(4.0-7.2) \ddagger$ & 0 & $<0.001$ \\
\hline \multicolumn{6}{|l|}{ Cardiac factors } \\
\hline No cardiac disorder & 0 & & $464(100)$ & 0 & $\mathrm{~N} / \mathrm{A}$ \\
\hline Cardiac prognostic severity (CPS) & & $1(<1)$ & N/A & & \\
\hline Curative & $102(21)$ & & & & \\
\hline Corrective & $272(57)$ & & & & \\
\hline Palliative & $103(22)$ & & & & \\
\hline Number of cardiac interventions & $2.0[1.0-3.0] \ddagger$ & 52 & 0 & 0 & $\mathrm{~N} / \mathrm{A}$ \\
\hline \multicolumn{6}{|c|}{$\begin{array}{l}\text { *Mean (SD). } \\
\text { †Includes carers/guardians. } \\
\text { ¥Median [IQR] based on parent questionnaire (parents reported all interventions where hospital case notes were incomplete and missing data reflects where parents could not provide } \\
\text { data). } \\
\text { §Number of occasions child takes part in a sporting activity (not school PE) per week. }\end{array}$} \\
\hline
\end{tabular}

Many studies involved only a single CHD diagnosis; 23 26-28 therefore, generalisability is limited. Although methodological differences limit direct comparison with our findings, studies involving paediatric chronic disease groups have demonstrated reductions in PedsQL scores comparable with $\mathrm{CHDs}$, for children with end-stage renal disease, epilepsy and cystic fibrosis, ${ }^{21} 2229$ while children with diabetes experience less reduction in QoL. ${ }^{21}$ 
Summary score
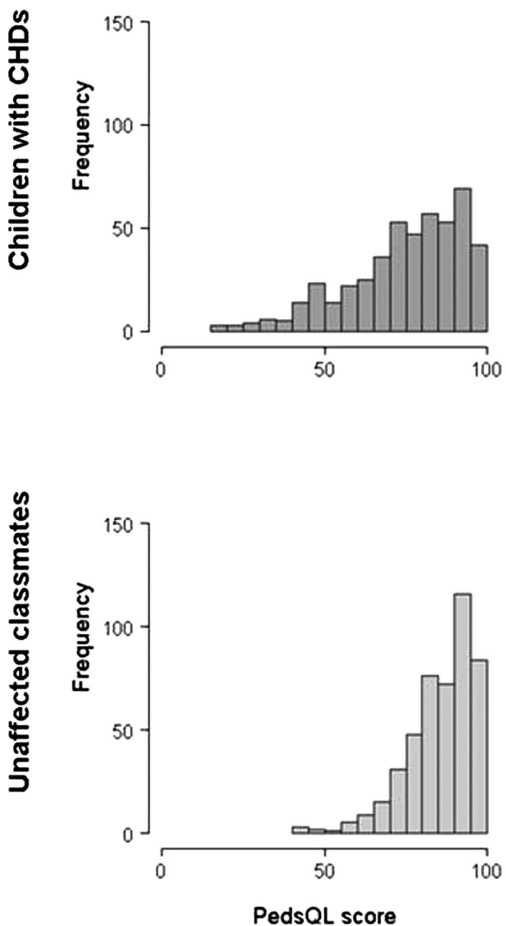

Physical functioning
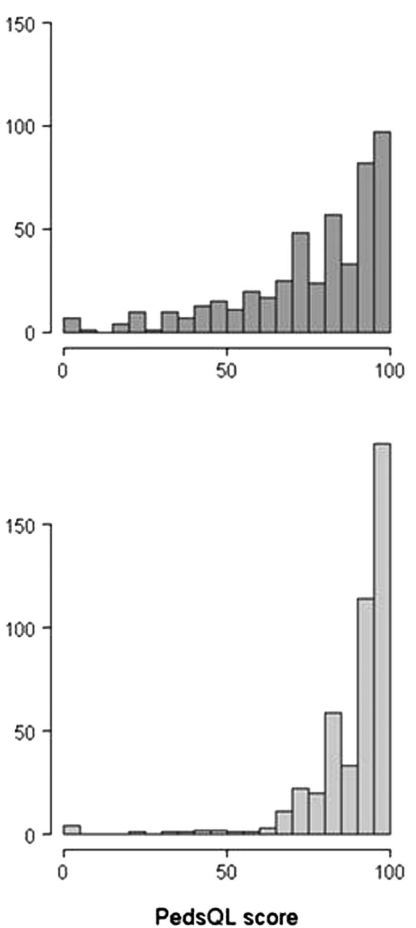

Psychosocial functioning
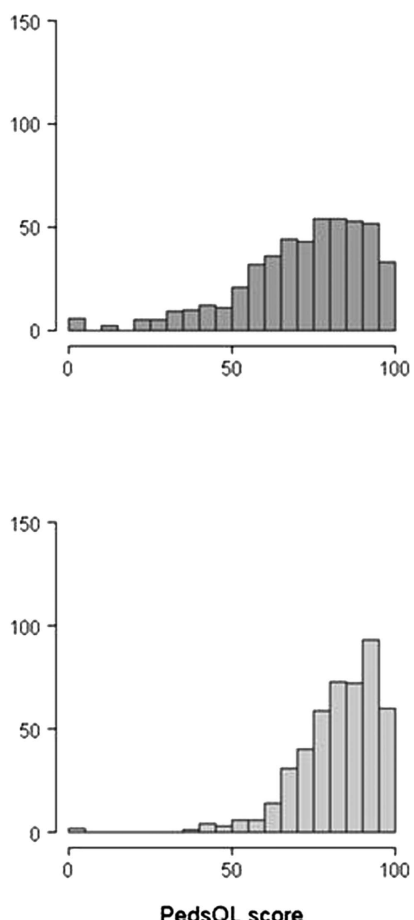

Figure 2 Unadjusted median PedsQL scores for children with CHDs ( $n=477)$ compared with unaffected classmates $(n=464)$.

Table 2 Multivariable models to investigate factors associated with PedsQL outcome scores

\begin{tabular}{|c|c|c|c|c|c|c|c|c|c|}
\hline \multirow[b]{2}{*}{ PedsQL } & \multicolumn{3}{|c|}{ PedsQL summary score } & \multicolumn{3}{|c|}{ Physical functioning } & \multicolumn{3}{|c|}{ Psychosocial functioning } \\
\hline & Est. & SE & $\mathrm{p}$ Value & Est. & SE & $\mathrm{p}$ Value & Est. & SE & $\mathrm{p}$ Value \\
\hline \multicolumn{10}{|l|}{ Individual factors } \\
\hline Presence of CHD & -2.58 & 0.77 & $<0.001$ & -1.70 & 0.57 & 0.003 & -2.35 & 0.93 & 0.01 \\
\hline Female & -0.29 & 0.77 & 0.71 & -0.91 & 0.57 & 0.11 & 0.27 & 0.87 & 0.76 \\
\hline Age & -0.30 & 0.38 & 0.42 & -0.42 & 0.29 & 0.15 & -0.12 & 0.44 & 0.78 \\
\hline White & -0.12 & 1.70 & 0.95 & 0.41 & 1.21 & 0.73 & 0.03 & 2.07 & 0.99 \\
\hline Birth weight (per kg) & -0.32 & 0.57 & 0.58 & -0.66 & 0.37 & 0.07 & 0.016 & 0.71 & 0.98 \\
\hline \multicolumn{10}{|l|}{ Parent $\dagger$ and family factors } \\
\hline \multicolumn{10}{|l|}{ Parental education } \\
\hline None/General Certificate of Secondary Education & ref & 0.94 & 0.73 & ref & 0.79 & 0.45 & ref & 1.06 & 0.96 \\
\hline A level & 0.33 & 0.89 & 0.83 & 0.59 & 0.72 & 0.56 & -0.05 & 1.03 & 0.77 \\
\hline Degree & 0.19 & & & 0.42 & & & 0.30 & & \\
\hline Number of full-time equivalent working parents $t$ & -0.09 & 0.81 & 0.91 & -0.24 & 0.72 & 0.74 & -0.35 & 0.92 & 0.71 \\
\hline Number of siblings at home & 6.09 & 8.16 & 0.46 & 7.12 & 5.80 & 0.21 & 3.44 & 8.98 & 0.70 \\
\hline Two parentst at home now & -4.63 & 8.20 & 0.57 & -7.38 & 5.71 & 0.20 & -1.23 & 9.05 & 0.89 \\
\hline Two parentst at birth & -1.23 & 1.75 & 0.48 & -0.46 & 1.61 & 0.78 & -2.37 & 2.12 & 0.27 \\
\hline Mother's age at birth & 0.09 & 0.11 & 0.42 & -0.07 & 0.09 & 0.44 & 0.12 & 0.13 & 0.33 \\
\hline Father's age at birth & -0.01 & 0.10 & 0.94 & 0.04 & 0.07 & 0.53 & -0.01 & 0.11 & 0.91 \\
\hline \multicolumn{10}{|l|}{ Comorbidities } \\
\hline \multicolumn{10}{|l|}{ Non-cardiac long-standing illness } \\
\hline None & ref & 1.17 & 0.88 & ref & 0.99 & 0.52 & ref & 1.35 & 0.57 \\
\hline Yes, not limiting & -0.17 & 1.04 & $<0.001$ & -0.64 & 1.14 & $<0.001$ & -0.76 & 1.19 & $<0.001$ \\
\hline Yes, limiting & -5.71 & & & -2.25 & & & -6.20 & & \\
\hline Uses regular medications & -3.74 & 0.98 & $<0.001$ & -2.45 & 0.91 & 0.008 & -2.90 & 1.12 & 0.001 \\
\hline Problems with vision & -1.90 & 0.85 & 0.03 & -0.68 & 0.68 & 0.32 & -1.85 & 0.98 & 0.06 \\
\hline Problems with hearing & -2.32 & 0.97 & 0.02 & -1.00 & 0.74 & 0.18 & -2.05 & 1.11 & 0.06 \\
\hline Problems with speech & 2.04 & 1.58 & 0.20 & 1.91 & 1.57 & 0.24 & -0.16 & 1.67 & 0.92 \\
\hline
\end{tabular}


Table 3 Multivariable models to investigate the additional effect on PedsQL outcome scores of daily life activities and cardiac severity (children with CHDs only)

\begin{tabular}{|c|c|c|c|c|c|c|c|c|c|}
\hline \multirow[b]{2}{*}{ PedsQL } & \multicolumn{3}{|c|}{ PedsQL summary score } & \multicolumn{3}{|c|}{ Physical functioning } & \multicolumn{3}{|c|}{ Psychosocial functioning } \\
\hline & Est. & SE & p Value & Est. & SE & p Value & Est. & SE & p Value \\
\hline \multicolumn{10}{|l|}{ A: Daily life activities $\ddagger$} \\
\hline \multicolumn{10}{|l|}{ School absence in last year } \\
\hline Never & ref & 1.07 & 0.20 & ref & 0.82 & 0.46 & ref & 1.00 & 0.07 \\
\hline$<1$ week & -1.37 & 1.23 & $<0.001$ & -0.60 & 0.95 & 0.03 & -1.79 & 1.40 & 0.002 \\
\hline $1-2$ weeks & -4.46 & 1.65 & & -2.12 & 1.21 & 0.003 & -4.43 & 1.84 & 0.004 \\
\hline 2 weeks-1 month & -5.29 & 1.81 & 0.001 & -3.54 & 1.56 & 0.23 & -5.33 & 2.69 & $<0.001$ \\
\hline$>1$ month & -10.12 & & $<0.001$ & -1.87 & & & -10.38 & & \\
\hline Frequency of sport* & 0.86 & 0.40 & 0.003 & 0.21 & 0.28 & 0.56 & 0.89 & 0.41 & 0.03 \\
\hline Frequency of social activitiest & -0.08 & 0.20 & 0.68 & 0.05 & 1.58 & 0.76 & -0.18 & 0.22 & 0.40 \\
\hline \multicolumn{10}{|c|}{ B: Cardiac severity (children with CHDs only)§ } \\
\hline \multicolumn{10}{|c|}{ Cardiac factors } \\
\hline \multicolumn{10}{|l|}{ Cardiac Prognostic Severity (CPS) } \\
\hline Curative & ref & 1.55 & 0.45 & ref & 1.25 & 0.68 & ref & 1.81 & 0.35 \\
\hline Corrective & -1.17 & 1.35 & 0.91 & 0.52 & 1.11 & 0.93 & -1.8 & 1.57 & 0.94 \\
\hline Palliative & 0.14 & & & 0.09 & & & 0.11 & & \\
\hline Number of cardiac interventions & -0.74 & 0.16 & $<0.001$ & -0.56 & 0.21 & 0.007 & -0.69 & 0.19 & $<0.001$ \\
\hline
\end{tabular}

Our prospective population-based study included all UK paediatric cardiac surgical centres and is representative of children born during the 1990s with a CHD requiring intervention. Only children who had a cardiac intervention before the age of 1 year were included, nevertheless few children with complex and significant CHDs will have been excluded by this pragmatic definition of severity. ${ }^{14}{ }^{30}$ Although governance restrictions limited the questionnaire to two-thirds of survivors, ${ }^{16}$ we achieved $60 \%$ response rate from families and comparison of respondent and non-respondent characteristics did not indicate systematic bias. A limitation of our postal survey method is that we are unable to verify whether children completed their questionnaires without support or influence from others and, as noted above, some children with learning difficulties were unable to complete their questionnaire. Children with palliated defects appeared more likely to respond; however, these children also had more frequent outpatient visits so their contact details were more likely to be current. Over 400 classmates comprised our healthy comparison group, thus avoiding reliance on population norms and facilitating analysis of factors associated with QoL. Importantly, mean classmate PedsQL scores were similar to those previously reported for healthy children. ${ }^{31}$ To take account of the non-normal distribution of participant factors and outcome scores, we employed non-parametric statistical methods, including GAMLSS regression models. To our knowledge this is the first time that regression analyses have adjusted for the skewed distribution of PedsQL scores using these methods.

Children in our study were more likely to experience reduced QoL if they could not attend school or take part in sport; however, QoL was not significantly improved by participation in

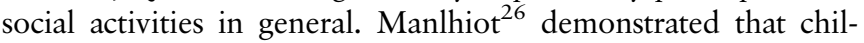
dren with CHDs who have healthy siblings have reduced QoL, suggesting that affected children may compare their physical abilities unfavourably with a 'normal' sibling. Interestingly, affected children in our cohort who participated regularly in sport scored higher on psychosocial functioning than children who did not, although there was no significant difference in selfreported physical functioning scores. Several researchers have also shown that regular involvement in sports or vigorous recreational physical activity benefits children's well-being and reduces emotional and behavioural problems. ${ }^{32} 33$ It is clear that participation in sporting or social activities represents a complex mediator of risk, influenced partly by the physical limitation imposed by a CHD. It is conceivable that some children with CHDs who participate fully in school and sports rate their psychosocial QoL high despite scoring their physical functioning lower, because they understand implicitly that they are 'successfully' negotiating the physical limitations of their condition.

Our study explores the impact of living with a CHD for children who have a range of defects, many of which might be considered surgically 'corrected' in infancy. Crucially, the mediating factors that might protect children from adverse QoL outcomes are likely to differ between individuals and may change over time. ${ }^{9}$ Experiencing recent or frequent health interventions may increase awareness of CHD as an ongoing health burden, with a consequent negative impact on QoL. We found decreased QoL associated with regular medication or cardiac interventions; in contrast, diagnostic severity was not an independent predictor of QoL. Greater attention may therefore need to be paid to the cumulative burden of interventions and medical care experienced by young patients.

PROMs are a key development as many healthcare outcomes, such as reduced symptoms or improvements in functional status and QoL, can only be assessed by patients. ${ }^{7}$ PROMS are increasingly being used to support shared decision-making between patients and clinicians. ${ }^{34}$ We have demonstrated the feasibility of using the PedsQL to obtain patient-reported outcomes for UK children living with a CHD. The added benefit of using measures designed specifically to capture the child's perspective has 
been clearly highlighted. ${ }^{35}$ Paediatric patient-report measures should be considered for integration into routine monitoring of chronic childhood disorders, and specifically to enrich cardiac audit and provide an additional source for evaluating and effecting improvements in care. A child-centred approach is fundamental to communication between children, families, health and education professionals about individual care, as well as to promoting good coping strategies and social inclusion to enhance the lives of children with CHDs for whom long-term survival in adulthood is now a realistic expectation.

Acknowledgements We are very grateful to the local cardiologists and members of the British Congenital Cardiac Association (BCCA) in each UKCSCHD collaborating centre, without whom this study would not have been possible: Dr S Adwani, Dr F Bu'Lock, Dr B Craig, Dr P Daubeney, Dr G Derrick, Dr M Elliott, Dr R Franklin, Dr J Gibbs, Dr B Knight, Dr J Lim, Dr A Magee, Dr R Martin, Dr P Miller, Dr S Qureshi, Dr E Rosenthal, Dr A Salmon, Dr I Sullivan, Dr P Thakker, Dr J Thomson, Dr D Wilson, Dr A Wong. UKCSCHD collaborating centres included: Belfast, Birmingham, Bristol, Cardiff, Edinburgh, Glasgow, Leeds, Leicester, Liverpool, London, Manchester, Newcastle, Nottingham, Oxford and Southampton. We would also like to thank the UKCSCHD research assistants (Ms Ugochi Nwulu, Dr Carly Rich and others) for their valuable contribution and hard work. In addition, we appreciate very much the support that we received from Heartline (parent support group).

Collaborators UK Collaborative Study of Congenital Heart Defects; UKCSCHD; Satish Adwani; Frances Bu'Lock; Brian Craig; Piers Daubeney; Graham Derrick; Martin Elliott; Rodney Franklin; John Gibbs; Brodie Knight; Joyce Lim; Alan Magee; Rob Martin; Paul Miller; Shakeel Qureshi; Eric Rosenthal; Anthony Salmon; Ian Sullivan; Pradip Thakker; John Thomson; Dirk Wilson; Amos Wong.

Contributors All authors have contributed substantially to the study, approved the final version of the manuscript and share responsibility for the results. RLK, CD, CB and CW conceptualised and designed the study, designed the data collection instruments and undertook data collection. TD, RLK and AW undertook analyses; all authors reviewed the analyses. RLK and TD drafted the manuscript. All authors critically reviewed and approved the final manuscript. The guarantor for this study is RLK.

Funding RLK was awarded an MRC Special Training Fellowship in Health of the Public and Health Services Research (reference G106/1083). TD was supported by an NIHR Academic Clinical Fellowship. This work was supported by a British Heart Foundation project grant (reference PG/02/065/13934). The Centre for Paediatric Epidemiology and Biostatistics benefits from funding support from the Medical Research Council in its capacity as the MRC Centre of Epidemiology for Child Health (reference G04005546). Great Ormond St Hospital for Children NHS Trust and the UCL Institute of Child Health receives a proportion of funding from the Department of Health's NIHR Biomedical Research Centres scheme. The funders had no role in the study design, data analysis and interpretation, writing or publication of this paper.

\section{Competing interests None.}

Ethics approval Ethics approval was given by Trent MREC (ref: 04/4/017). Adult participants provided signed consent; children provided signed assent.

Provenance and peer review Not commissioned; externally peer reviewed.

Data sharing statement Unpublished data are not available for sharing outside of the UKCSCHD collaborating centres.

Open Access This is an Open Access article distributed in accordance with the terms of the Creative Commons Attribution (CC BY 3.0) license, which permits others to distribute, remix, adapt and build upon this work, for commercial use, provided the original work is properly cited. See: http://creativecommons.org/licenses/ by/3.0/

\section{REFERENCES}

1 Boneva RS, Botto LD, Moore CA, et al. Mortality associated with congenital heart defects in the United States: trends and racial disparities, 1979-1997. Circulation 2001;103:2376-81.

2 Latal B, Helfricht S, Fischer JE, et al. Psychological adjustment and quality of life in children and adolescents following open-heart surgery for congenital heart disease: a systematic review. BMC Pediatr 2009:9:6.

3 Bristol Royal Infirmary Inquiry (Chairman: Professor lan Kennedy). The Bristol Inquiry. Learning from Bristol: the report of the public inquiry into children's heart surgery at the Bristol Royal Infirmary 1984-1995. Norwich: The Stationery Office, 2001.

4 NICOR. National Institute for Cardiovascular Outcomes Research: Central Cardiac Audit Database. http://www.ucl.ac.uk/nicor/audits/congenitalheartdisease (accessed 23 Aug 2013).
5 Department of Health (England). High quality care for all: NHS next stage review final report. London: The Stationery Office, 2008. http://www.official-documents. gov.uk/document/cm74/7432/7432.pdf (accessed 23 Aug 2013).

6 Snyder CF, Aaronson NK. Use of patient-reported outcomes in clinical practice. Lancet 2009;374:369-70.

7 Black N. Patient reported outcome measures could help transform healthcare. BMJ 2013;346:f167.

8 Upton P, Lawford J, Eiser C. Parent-child agreement across child health-related quality of life instruments: a review of the literature. Qual Life Res 2008;17:895-913.

9 Lawford J, Eiser C. Exploring links between the concepts of Quality of Life and resilience. Pediatr Rehabil 2001;4:209-16.

10 Uzark K, Jones K, Slusher J, et al. Quality of life in children with heart disease as perceived by children and parents. Pediatrics 2008;121:e1060-7.

11 Eiser C, Morse R. A review of measures of quality of life for children with chronic illness. Arch Dis Child 2001;84:205-11.

12 Marino BS, Shera D, Wernovsky G, et al. The development of the pediatric cardiac quality of life inventory: a quality of life measure for children and adolescents with heart disease. Qual Life Res 2008;17:613-26.

13 Varni JW, Burwinkle TM, Seid M. The PedsQLTM as a pediatric patient-reported outcome: reliability and validity of the PedsQLTM Measurement Model in 25,000 children. Expert Rev Pharmacoecon Outcomes Res 2005:5:705-19.

14 Wren C, Richmond S, Donaldson L. Temporal variability in birth prevalence of cardiovascular malformations. Heart 2000;83:414-19.

15 Lane DA, Lip GY, Millane TA. Quality of life in adults with congenital heart disease. Heart 2002:88:71-5

16 Knowles RL, Bull C, Wren C, et al. Ethics, governance and consent in the UK: implications for research into the longer-term outcomes of congenital heart defects. Arch Dis Child 2011:96:14-20.

17 OPCS. General household survey, number 22. London: HMSO, 1991

18 Bonett DG, Price RM. Statistical inference for a linear function of medians: confidence intervals, hypothesis testing, and sample size requirements. Psychol Methods 2002;7:370-83.

19 Rigby RA, Stasinopoulos DM. Generalized additive models for location, scale and shape. App/ Stat 2005;54:507-54.

20 Jones MC, Pewsey A. Sinh-arcsinh distributions. Biometrika 2009;96:761-80

21 Varni J, Limbers C, Burwinkle T. Impaired health-related quality of life in children and adolescents with chronic conditions: a comparative analysis of 10 disease clusters and 33 disease categories/severities utilizing the PedsQL ${ }^{\mathrm{TM}} 4.0$ Generic Core Scales. Health Qual Life Outcomes 2007:5:43.

22 Ingerski LM, Modi AC, Hood KK, et al. Health-related quality of life across pediatric chronic conditions. J Pediatr 2010;156:639-44.

23 Gaies MG, Watnick CS, Gurney JG, et al. Health-related quality of life in patients with congenitally corrected transposition of the great arteries. J Thorac Cardiovasc Surg 2011;142:136-41.

24 Tahirović $\mathrm{E}$, Begić $\mathrm{H}$, Nurkić $\mathrm{M}$, et al. Does the severity of congenital heart defects affect disease-specific health-related quality of life in children in Bosnia and Herzegovina? Eur J Pediatr 2010;169:349-53.

25 Berkes A, Varni J, Pataki I, et al. Measuring health-related quality of life in Hungarian children attending a cardiology clinic with the Pediatric Quality of Life Inventory TM. Eur J Pediatr 2010;169:333-47.

26 Manlhiot C, Knezevich S, Radojewski E, et al. Functional health status of adolescents after the Fontan procedure-comparison with their siblings. Can J Cardiol 2009;25:e294-300.

27 Kwon EN, Mussatto K, Simpson PM, et al. Children and adolescents with repaired tetralogy of fallot report quality of life similar to healthy peers. Congenit Heart Dis 2011:6:18-27.

28 Idorn L, Jensen AS, Juul K, et al. Quality of life and cognitive function in Fontan patients, a population-based study. Int I Cardiol 2013;168:3230-5

29 Thomas C, Mitchell P, O'Rourke P, et al. Quality-of-life in children and adolescents with cystic fibrosis managed in both regional outreach and cystic fibrosis center settings in Queensland. J Pediatr 2006;148:508-16.

30 Bull C. Current and potential impact of fetal diagnosis on prevalence and spectrum of serious congenital heart disease at term in the UK. British Paediatric Cardiac Association. Lancet 1999;354:1242-7.

31 Upton P, Eiser C, Cheung I, et al. Measurement properties of the UK-English version of the Pediatric Quality of Life Inventory 4.0 (PedsQL) generic core scales. Health Qual Life Outcomes 2005;3:22.

32 Griffiths LJ, Dowda M, Dezateux C, et al. Associations between sport and screen-entertainment with mental health problems in 5-year-old children. Int J Behav Nutr Phys Act 2010;7:30

33 Steptoe A, Butler N. Sports participation and emotional wellbeing in adolescents. Lancet 1996:347:1789-92.

34 Stiggelbout AM, Van der Weijden T, De Wit MP, et al. Shared decision making: really putting patients at the centre of healthcare. BMJ 2012;344:e256.

35 Morris C, Gibbons E, Fitzpatrick R. Child and parent reported outcome measures: a scoping report focusing on feasibility for routine use in the NHS. A report to the Department of Health. Oxford: Patient-reported Outcomes Measurement Group, Dept. of Public Health, University of Oxford, 2009. 